\section{The impact of rheumatoid factor and ACPA on bone erosion in rheumatoid arthritis}

In their letter, Van Steenbergen and colleagues present data on the radiographic progression in rheumatoid arthritis (RA) patients stratified for anti-citrullinated protein antibody (ACPA) and rheumatoid factors (RFs) in two different patient cohorts. ${ }^{1}$ They show that the presence of ACPA is associated with a more pronounced progression of structural damage when scoring conventional radiographs by the standardised Sharp-van der Heijde method. ${ }^{1}$ These findings (i) underline previous radiographic findings that ACPAs are associated with radiographic progression in $\mathrm{RA}^{2}$ (ii) stay in line with the known pathophysiologic function of ACPA in osteoclast differentiation ${ }^{3}$ and (iii) also support our high-resolution CT data showing the relevance of ACPA in bone erosions. $^{4}$

The authors, however, found no difference in radiographic progression whether RF was present or not. At first sight, this finding seems to contradict our recently published highresolution CT data, where we could dissect the role of ACPA and $\mathrm{RF}$ on bone erosion showed that RF also affects bone loss in RA patients in addition to ACPA. ${ }^{4}$ However, limitations of conventional radiographs are likely being a simple explanation for the fact that Van Steenbergen and colleagues were not able to detect differences between RF-positive and RF-negative individuals. Based on the $2 \mathrm{D}$ nature and its limited resolution, a substantial number of erosions escape their detection by conventional radiography when compared with high-resolution $\mathrm{CT}^{5}$ The latter technique with a resolution of slightly more than $100 \mu \mathrm{m}$ can even detect very small lesions with a volume of less than $1 \mathrm{~mm}^{3}$, independent at which anatomical site they are localised. Hence, we believe that the detection threshold with respect to lesion size and localisation for conventional radiography is simply too high to pick up the more subtle differences in erosions; one can accurately pick up by high-resolution CT. This situation creates an 'insufficient' signal-to noise ratio to detect a certain process, which cannot simply be compensated by increasing the sample size or including more joints without changing the method itself. Hence, the intrinsic limitations of the method will be still present even when increasing the number of measurements.

Although we think that the aforementioned point sufficiently explains these differences between our approach and the one by Van Steenbergen and colleagues, another important factor may additionally affect the results presented in this letter: RF, in contrast to ACPA, is much more linked to disease activity. Hence, effective treatment of RA, which for sure has been initiated in the patients included in these two cohorts, may have cleared the RF-immune complexes in these patients over time and level out the differences between the two groups of ACPA-positive RA patients.

\section{Carolin Hecht, Georg Schett, Stephanie Finzel}

Department of Internal Medicine 3, University of Erlangen-Nuremberg, Erlangen, Germany

Correspondence to Professor Georg Schett, Department of Rheumatology, University of Erlangen, Erlangen 91054, Germany; georg.schett@uk-erlangen.de

Competing interests None.

Provenance and peer review Commissioned; internally peer reviewed.

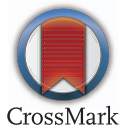

To cite Hecht C, Schett G, Finzel S. Ann Rheum Dis 2015;74:e4.

Received 20 September 2014

Accepted 29 September 2014

Published Online First 17 October 2014

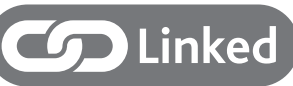

http://dx.doi.org/10.1136/annrheumdis-2014-206623

Ann Rheum Dis 2015;74:e4. doi:10.1136/annrheumdis-2014-206631

\section{REFERENCES}

1 van Steenbergen HW, Ajeganova S, Forslind $\mathrm{K}$, et al. The effects of rheumatoid factor and anticitrullinated peptide antibodies on bone erosions in rheumatoid arthritis. Ann Rheum Dis 2015;74:e3.

2 van derHelm-van Mil AH, Mil AH, Verpoort KN, Breedveld FC, et al. Antibodies to citrullinated proteins and differences in clinical progression of rheumatoid arthritis. Arthritis Res Ther 2005;7:R949-58.

3 Harre U, Georgess D, Bang $\mathrm{H}$, et al. Induction of osteoclastogenesis and bone loss by human autoantibodies against citrullinated vimentin. J Clin Invest 2012:122:1791-802.

4 Hecht C, Englbrecht M, Rech J, et al. Additive effect of anti-citrullinated protein antibodies and rheumatoid factor on bone erosions in patients with RA. Ann Rheum Dis 2014. Published Online First: 12 Aug 2014. doi: 10.1136/annrheumdis-2014205428

5 Stach CM, Bauerle M, Englbrecht M, et al. Periarticular bone structure in rheumatoid arthritis patients and healthy individuals assessed by high-resolution computed tomography. Arthritis Rheum 2010;62:330-9. 